\title{
Correction to: Factors Associated with Reoperation in Breast- Conserving Surgery for Cancer: A Prospective Study of American Society of Breast Surgeon Members
}

\author{
Jeffrey Landercasper, MD, FACS ${ }^{1,2}$, Andrew J. Borgert, PhD ${ }^{2}$, Oluwadamilola M. Fayanju, MD, MA, MPHS ${ }^{3}$, \\ Hiram Cody III, $\mathrm{MD}^{4}$, Sheldon Feldman, $\mathrm{MD}^{5}$, Caprice Greenberg, MD, MPH, FACS ${ }^{6}$, Jared Linebarger, MD ${ }^{1,7}$, \\ Barbara Pockaj, $\mathrm{MD}^{8}$, and Lee Wilke, MD, FACS ${ }^{6}$ \\ ${ }^{1}$ Norma J. Vinger Center for Breast Cancer, Gundersen Health System, La Crosse, WI; ${ }^{2}$ Department of Medical Research, \\ Gundersen Medical Foundation, La Crosse, WI; ${ }^{3}$ Department of Surgery, Duke University Medical Center, Durham, NC; \\ ${ }^{4}$ Department of Surgery, Memorial Sloan Kettering Cancer Center, New York, NY; ${ }^{5}$ Montefiore Einstein Center for Cancer \\ Care, Montefiore Medical Center, Bronx, NY; ${ }^{6}$ University of Wisconsin School of Public Health and Medicine, Madison, \\ WI; ${ }^{7}$ Department of Surgery, Gundersen Health System, La Crosse, WI; ${ }^{8}$ Department of Surgery, Mayo Clinic, Phoenix, \\ $\mathrm{AZ}$
}

Correction to: Ann Surg Oncol https://doi.org/10.1245/s10434-019-07547-w

The Disclosures in the original article are incomplete. Not included is the following information:

Dr. Wilke also served in the following roles: site PI (non-compensated) for a clinical trial evaluating an optical breast tumor margin assessment device (Perimeter Medical Imaging), co-I (partial compensation) of an NIH/NIBIB R01 (R01EB020521)-funded clinical trial evaluating breast tissue imaging of mastectomy specimens, and site PI (partial compensation) of an optical intraoperative breast tumor margin assessment device through a subcontract from Duke University, NIH R01 (EB011574).

The following is the complete Disclosures section:

Andrew Borgert and Dr. Landercasper received funding from the Gundersen Medical Foundation; however, this is unrelated to the content of this manuscript. Dr. Fayanju was supported by the National Center for Advancing Translational Sciences of the National Institutes of Health
(NIH) under Award Number 1KL2TR002554 (PI: Svetkey) and by the Duke Cancer Institute through NIH grant P30CA014236 (PI: Kastan). The content of this manuscript is solely the responsibility of the authors and does not necessarily represent the official views of the NIH. Dr. Cody, Dr. Feldman, Dr. Linebarger, and Dr. Pockaj have no disclosures. Dr. Greenberg is a consultant for Johnson and Johnson on their Global Education Council; this is unrelated to the content of this manuscript. Dr. Wilke is a founder and minority stock owner in Elucent Medical; this is unrelated to the content of this manuscript. Dr. Wilke also served in the following roles: site PI (non-compensated) for a clinical trial evaluating an optical breast tumor margin assessment device (Perimeter Medical Imaging), co-I (partial compensation) of an NIH/NIBIB R01 (R01EB020521)-funded clinical trial evaluating breast tissue imaging of mastectomy specimens, and site PI (partial compensation) of an optical intraoperative breast tumor margin assessment device through a subcontract from Duke University, NIH R01 (EB011574).

The original article can be found online at https://doi.org/10.1245/ s10434-019-07547-w.

(c) The Author(s) 2019

Published Online: 11 September 2019

J. Landercasper, MD, FACS

e-mail: JLanderc@gundersenhealth.org 